\title{
Research on the Bond-anchorage Behavior of HRB500 Bundled Bars
}

\section{LIU Qing-wen 1,2,a, TANG Bin ${ }^{1, b}$, Subesh Bhattarai ${ }^{1, c}$, GAO Cheng-hui ${ }^{1, d}$}

${ }^{1}$ School of Civil Engineering and Architecture, Nanchang Hangkong University, nanchang 330063, China;

${ }^{2}$ Key Laboratory of Hydraulic \& Waterway Engineering of the Ministry of Education, Chongqing Jiaotong University, Chongqing 400074, China

aqingwenliu@126.com, b1343869321@qq.com, csubsonic571@qq.com, d3242475062@qq.com

Keywords: high-strength reinforcement, bundled bar, bond-anchorage behavior

Abstract. The pullout experiments of 9 HRB500 bond-anchorage specimens are carried out. The influence of the quantity of bundled bars, anchorage length on the bond-anchorage behavior of HRB500 bundled bars is comparatively analysed. The load slip curve of bundled bar is obtained, and the bond-anchoring mechanism between steel bar and concrete is analysed. Studies show that there are two failure patterns of HRB500 bundled bar which are pull-out failure and splitting failure. Average bond-anchoring strength decrease with increasing of number of steel bars and anchorage length.

\section{Introduction}

In the structure of the building, structural members with large load and span are intensively reinforced which lead to construction difficulties. In practice, reinforcement scheme is often used to solve this problem. The configuration of reinforcement changes from single bars to bundled and hence the bonding anchoring performance with concrete may change. From the 1940s, the American Concrete Council, Homer M.Hadley and BashandyT R carried out the experimental research on the bundled bars beam, compared with the bearing capacity of conventional reinforced concrete beams. It is considered that the bearing capacity of bundled bars concrete beam and conventional reinforced concrete beam are basically the same[1,2]. The United States code incorporated bundled bars into concrete structural specifications at 1960s[3]. Xu You-ling from China Academy of Building Research and LIU Li-xin from Zhengzhou University carried out research on ordinary bundled bars[4-6]. However, there is no research on high-strength bundled bars. Chinese code for design of concrete structures(GB50010-2010) put forward the arrangement of bundled bars[7].

In particular, high strength steel bars like HRB500 steel bar may affect the force performance of members. Therefore, the impact of high strength bundled bars on concrete members needs to be studies. In this paper, high-strength bundled bars pull-out tests are carried out to study the bonding and anchoring

\section{Experimental Program}

\section{Specimen and Material Details}

The pull-out tests of HRB500 steel bars were carried out. Steel bars were arranged for singly, doubly and triply in concrete specimens. The actual yield strength of steel bar is $556.5 \mathrm{MPa}$. the diameter of a single steel bar is $14 \mathrm{~mm}$, and the diameter of bundled bars adopt equivalent diameter. The actual cube compressive strength of concrete is $37.8 \mathrm{MPa}$. The specific parameters of specimens are shown in Tab.1. The arrangement of bundled bars is shown in Fig.1.

\section{Testing Procedure}

A 90mm long PVC sleeve was placed at the loading end of the specimen to form an unbonded zone to prevent the interference caused by local crushing damage. The load of the specimen was recorded by powertest software in universal testing machine. The experiment was completed by sans electro-hydraulic servo testing machine and operated according to the provisions of test method 
standard for concrete structure. During the experiment, the experimental device was installed in the test machine. The fixture above the test machine grips the rebar and the screw in the middle of the experimental device was kept constant and the reinforcing bar was drawn from the top. The test device and electro-hydraulic servo universal testing machine are shown in Fig. 2.

Tab.1 Properties of specimens

\begin{tabular}{cccccc}
\hline Layout of steel bar(No.) & $\begin{array}{c}\text { Equivalent } \\
\text { diameter of } \\
\text { bars(mm) }\end{array}$ & $\begin{array}{c}\text { Horizontal size } \\
\text { of specimen } \\
(\mathrm{mm} \times \mathrm{mm})\end{array}$ & $\begin{array}{c}\text { Length of } \\
\text { specimen }(\mathrm{mm})\end{array}$ & $\begin{array}{c}\text { Anchorage } \\
\text { length (mm) }\end{array}$ & $\begin{array}{c}\text { Concrete cover } \\
\text { thickness }(\mathrm{mm})\end{array}$ \\
\hline Single bar (S1) & 14 & $150 \times 150$ & 150 & 60 & 68 \\
Single bar (S2) & 14 & $150 \times 150$ & 190 & 100 & 68 \\
Single bar (S3) & 14 & $150 \times 150$ & 230 & 140 & 68 \\
Double bundled bars(D1) & $14 \sqrt{2}$ & $250 \times 250$ & 170 & 80 & 115 \\
Double bundled bars(D2) & $14 \sqrt{2}$ & $250 \times 250$ & 230 & 140 & 115 \\
Double bundled bars(D3) & $14 \sqrt{2}$ & $250 \times 250$ & 290 & 200 & 115 \\
Triple bundled bars(T1) & $14 \sqrt{3}$ & $250 \times 250$ & 190 & 100 & 113 \\
Triple bundled bars(T2) & $14 \sqrt{3}$ & $250 \times 250$ & 260 & 170 & 113 \\
Triple bundled bars(T3) & $14 \sqrt{3}$ & $250 \times 250$ & 330 & 240 & 113 \\
\hline
\end{tabular}

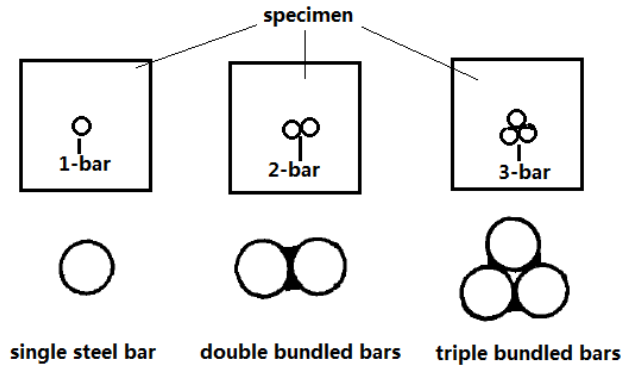

Fig.1 arrangement of bundled bars

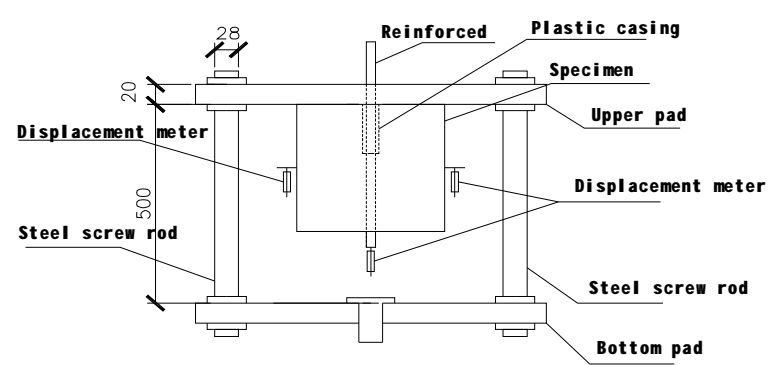

Fig.2 Test Device

\section{Test Damage Characteristics}

The pull-out tests showed that the specimens of S3, D1, D2, T2 and T3 underwent brittle splitting failure, with splitting cracks throughout the entire specimen. Failure of bonding anchors caused the specimen to break into pieces. Finally, the specimen splitting damage. The specimens of S1, S2, D3 and $\mathrm{T} 1$ underwent steel pull-out failure, and there was a slow development of splitting cracks. cracks could not penetrate through the concrete cover, so it did not develop till the free-end, the steel bar was pulled out slowly then occurred pullout failure.

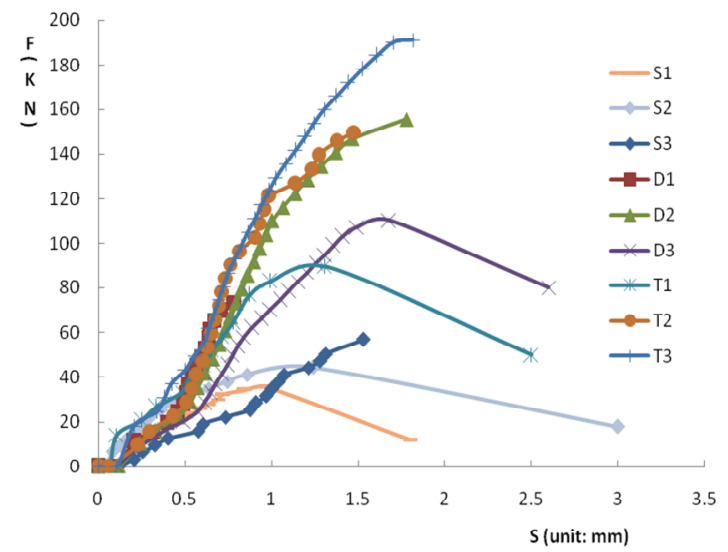

Fig. 3 Force-Slip curves

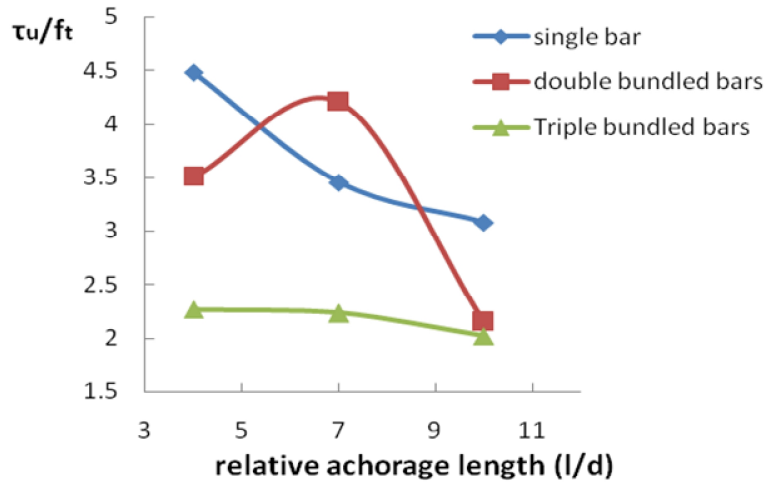

Fig.4 Relative achorage length-bond stress curves 


\section{Force-Slip curves}

Fig.3 shows the force-slip curve of pull-out test. (1) the ascending-only curve is for the specimen of the splitting failure which have only ascending section; (2) the ascending and descending curve is for the specimens which have ascending and descending sections.

The load slip curve of single reinforcement can be divided into five stages. However, since the specimens damaged by splitting collapsed into small pieces after the splitting failure, only the first three stages were involved:

1. The micro slip section: in the initial stage, the load was very small, the slip at the loading end was very small, and the free end did not slip.

2. Slip section: When the free end slip occurred, the slippage growth accelerated, showing a nonlinear state, indicating that cementation failure but depends on friction and mechanical adhesive force. The slip between the free end and the load end was slowly synchronized.

3. Split section: With the increase in pulling force, when the pulling force was loaded to a certain extent, the relative slip value would also increased though the pulling force did not increase.Then with the increase in pulling force, splitting failure occurred from the weakest part of the specimen and then gradually extended to the internal of the specimen and finally to the free end. Pulling force no longer increased, concrete brittle failure, divided into small pieces. If the concrete cover of the specimen was thicker, the specimen remained intact and the pullout failure of the steel bar occurred. For the split specimen, S3 only includes the first three stages, while for specimen S1and S2, because the concrete cover was thicker but the pull-force was small, so the splitting crack developed slowly. The crack could not penetrate the concrete cover. The reinforcement has been slowly pulled out until the pullout failure occurs ,but cracks have not yet developed to the free end So, their curves also include the falling and the remaining segments.

4. Descending section: for the specimen that occurred pullout failure, when the pull-force was loaded to the maximum value, the load decreased rapidly, but Slip value increases rapidly and there are visible cracks on the specimen.

5. The residual section: the pull-force was no longer reduced and remained unchanged, while the slip continued to grow until the reinforcement was gradually pulled out of the concrete. For the specimens with larger anchor length, the free end basically did not slip and the slip at the loading end no longer increased. The elongation of steel bars lead to the slip growth, and the surface of the specimen didn't change much. Finally, the steel bars yielded.

\section{Analysis of the main influencing factors of Bond-anchorage Behavior}

\section{Quantity of HRB500 bundled bars}

The bond stress slip curve of the steel bars is shown in Fig.4. From Fig.4 we can know that with the increase in the number of bars the total adhesive anchoring force of the triple bars and double bars increased. However, when converted into the average bond anchorage strength of each bar, the bond anchoring strength was found lower than that of a single bar. It was found that the greater the number of bars, the more pronounced the decrease.

\section{Anchorage length of HRB500 bundled bars}

Relationship between bond strength and anchor length is shown in Fig.5. From Fig.5 we can know that with the anchoring length increased, the pull-force became larger and the average bond strength decreased except the specimen D2. This is because the longer of the anchorage length, the more uneven the stress distribution. And the larger stress section is relatively short, so the average bond stress was decreased. For the shorter of anchorage length, the stress area was longer. The stress distribution was full, the average bonding stress increased. That is to say, due to the non-uniform distribution of bonding strength, when the pull-out test was carried out, the bonding stress of the loading end was larger and it decreased gradually when approached to the free end. The specimen with the longer anchoring length had a shorter area of high stress near the loading end, resulting in a decrease in the average bond anchoring strength. The average bond strength of D2 specimen was 
much larger than the calculated value. The reason for the increase is that the concrete infiltrates into the PVC pipe during the production process of the specimen and vibrates the concrete, resulting in a significant increase of the pulling force so that the average bonding strength increased.

\section{Conclusion}

1. The results of pull-out test that HRB500 reinforced anchorage force of two kinds of failure modes: splitting failure and pullout failure. Pullout failure can be divided into: Micro slip, slip, splitting, descending, residual, but the splitting failure includes only the micro-slip section, the slip section and the cleavage section.

2.The bond-anchorage mechanism of high strength bundled bars is consistent with that of bundled common strength bars. At the beginning of loading, the chemical bonding force is adopted to bear the slip force, and then the frictional force is taken, and finally transmitted to the mechanical adhesive force until the failure occurs.

3.The influence of quantity of bundled bars on the reinforcement of HRB500 shows that the more the number of bundled bars, the more obvious the decrease of the average bond strength of HRB500 bars.

4. The effect of anchorage length on the reinforcement of HRB500 is as follows: With the increase of anchorage length, the pulling force becomes larger, but the average bond-anchorage strength of HRB500 bundled bar decreases.

\section{Acknowledgements}

This work was financially supported by the National Natural Science Foundation of China(50968013), Chongqing Jiaotong University, National Engineering Research Center for Inland Waterway Regulation, Key Laboratory of Hydraulic and Waterway Engineering of Ministry of Education Open Foundation (SLK2016B01).

\section{References}

[1] Homer M. Hadley. Tests of Beams Reinforced with Bundle-Bars. Civil Engineering for February, 1941 VOL.ii No.2

[2] Bashandy T R. Evaluation of bundled bar lap splices. ACI Structural Journal, 2009, 106(2): 215-221.

[3] ACI Comnittee 408, Bond Stress-The State of the Art. ACI Journal, Proceedings, 1966, 63(11): 1161-1188.

[4] Xu You-ling. Experimental study of bond-anchorage Properties for bundled bars. Building Structure, 1996, (5): 34-37. in Chinese.

[5] LIU Li-xin, LAW Kwok-sang. Study on Anchorage Properties of Bundled Bars in Reinforced Concrete Beams. Journal of Zhengzhou University of Technology, 2001, 22(3):1-5.

[6] ZHAO Geng-qi, LI Qian, CHEN Meng, BI Su-ping. Study on Bearing Capacity of Abreast-arranged Deformed Bars in R.C. Beams. Journal of Zhengzhou University of Technology, 2001, 22(1):64-67. in Chinese.

[7] GB50010-2010,Code for design of concrete structures. in Chinese 